\title{
ESSenTIAL: EPIXfab Services Specifically Targeting (SME) Industrial Takeup of Advanced Silicon Photonics
}

\author{
J. Pozo ${ }^{1}$, P. Kumar ${ }^{1}$, D.M.R. Lo Cascio ${ }^{1}$, A. Khanna ${ }^{2}$, P. Dumon ${ }^{2}$, D. Delbeke ${ }^{2}$, R. Baets ${ }^{2}$, \\ M. Fournier ${ }^{3}$, J-M. Fedeli ${ }^{3}$, L. Fulbert ${ }^{3}$, L. Zimmermann ${ }^{4}$, B. Tillack ${ }^{4,5}$, H. Tian ${ }^{4}$, \\ T. Aalto ${ }^{6}$, P. O'Brien ${ }^{7}$, D. Deptuck ${ }^{8}$, J. Xu ${ }^{8}$, X. Zhang ${ }^{8}$, D. Gale ${ }^{8}$ \\ 1. TNO, Stieltjesweg 1, 2628CK, Delft, The Netherlands \\ 2 Photonics Research Group, Department of Information Technology, IMEC - Ghent University, \\ Sint-Pietersnieuwstraat 41.9000 Gent, Belgium \\ ${ }^{3 .}$ CEA, LETI, Minatec 17 rue des Martyrs, 38054 Grenoble, France \\ * IHP GmbH - Innovations for High Performance Microelectronics/Leibniz-Institut für innovative \\ Mikroelektronik, Im Technologiepark 25, 15236 Frankfurt (Oder), Germany \\ 3. Technische Universitaet Berlin, HFT4, Einsteinufer 25, 10587, Berlin, Germany \\ 6. VTT Technical Research Centre of Finland, Tietotie 3, 02150 Espoo, Finland \\ 7. Photonics Packaging Group, Tyndall National Institute, University College Cork, Ireland \\ 8. CMC Microsystems, Innovation Park, Kingston, Canada K7L $3 N 6$ \\ Tel: +31888660970,e-mail: jose.pozo@tno.nl
}

\begin{abstract}
ePIXfab brings silicon photonics within reach of European small and medium sized enterprises, thereby building on its track record and its integration into Europractice. To this end, ePIXfab offers affordable access to standardized active and passive silicon photonic IC and packaging technology, a path from design to manufacturing and hands-on training. Based on a consortium of major research institutes with silicon photonics expertise, ePIXfab reaches out to European industry and supports them to evaluate silicon photonics in the context of concrete applications and markets. In order to ensure low-cost, quick access and scalability to manufacturing, the maturity of silicon photonic IC technology is enhanced by setting up a library of generic devices, a level of process and device benchmarking and a well maintained design flow. For the first time, devices in a standard package are offered to facilitate measurements. Training programs on the IC and packaging services are also offered, including hands-on training in making designs. Maturity, standardization and sustainability are driven by a steadily growing worldwide user base.
\end{abstract}

Keywords: Silicon photonics, optical modulators, detectors, photonic packaging, grating couplers, multiproject wafer fabrication, industrial outreach.

\section{BACKGROUND}

Silicon photonics is the emerging, advanced optical technology that makes photonics compatible with CMOS technology. Silicon photonics enables the integration of complete optical systems on a monolithic semiconductor Silicon-on-Insulator (SOI) chip. SOI or CMOS technology is an extremely powerful technology platform that is today the basis of complex microprocessors, large memory circuits and a wide range of digital and analogue electronics. Standardization, yield, reliability, high volume and low cost are common in the CMOS microelectronics industry. With silicon photonics, the decades of research and manufacturing experience gained from the microelectronics industry can be utilised. Silicon photonics finally may bring standardization, yield, reliability, high volume and low cost to the optics industry; these are essential criteria in order to develop a competitive position.

From early on, access to silicon PIC technology has been set up by ePIXfab [1], initially collaboration between IMEC and CEA-LETI, and co-financed by FP7 support action PhotonFAB [2]. The PhotonFAB project has significantly lowered the barriers for access to silicon photonics for knowledgeable academic and industry researchers. Passive device technology was standardized, the design flow was improved, process technology for active devices was offered for the first time and training was introduced. The PhotonFAB project has opened up the technology for non-expert users, and has put fabless access on a level where the first companies have started to evaluate the technology. PhotonFAB has allowed access to mature passive device technology to Europractice in 2011 [3] and this access runs in a self-sustained mode.

With the new support action ESSenTIAL, by September 2014, ePIXfab will reach to the level of being an advanced and effective silicon photonics support centre for access to design, chip fabrication, packaging, training and support. A particular emphasis is placed on ensuring ease of access to Europe's SME sector. 


\section{SILICON PHOTONICS TRANSFER TO EUROPEAN INDUSTRY}

For a wide range of SMEs, it is only possible to explore and adopt an advanced technology in collaboration with major research institutes. ePIXfab organizes a number of critical support measures to enable European industry, and specifically SMEs, evaluate and develop silicon photonics technologies. This is achieved through access to a highly experienced consortium of partners, including some of Europe's major photonics research centres. The research institutions in the consortium already have a large industry network and are building on this network through a range of outreach activities to educate European industries about the means through which silicon photonics can be developed and evaluated.

\subsection{Feasibility studies and hands-on training}

ePIXfab supports this transfer through the organisation of dissemination, tutorials and training events, organized by the partners at their own facilities and by supporting first technology evaluations of SME business cases. ePIXfab supports the human resources to facilitate the initial technology feasibility study and manufacturing roadmap in collaboration with the SME, an initial go/no-go analysis to invest in further development.

\section{PHOTONIC CIRCUITS STANDARIZATION AND MULTI-PROJECT WAFER}

For both SMEs and academic researchers, cost-effectiveness and low-threshold are essential. ePIXfab supports access to advanced silicon photonics for SMEs and researchers by offering a cost-shared MPW service, and since 2006 one of the main tasks of this foundry has been the standardization of building blocks. Between 2012 and 2014, ePIXfab will standardize the current foundry offer so that cost-effective early R\&D on complex optical systems (involving passive and active devices) on a chip becomes possible.

\subsection{New generic building blocks}

Whereas previously only passive devices were standardized, ePIXfab will make also a number of active generic building blocks available. In this section, these new generic active building blocks are described by briefly reviewing some relevant consortium's publications. These generic devices will work at $1550 \mathrm{~nm}$ wavelength and have a performance useful for circuit and systems $R \& D$ on a wider range of applications, from datacom to sensing, not optimized for one specific application.

\subsubsection{Photodiodes based on monolithic Germanium integration.}

Lateral p-i-n germanium photodetectors are grown at the end of silicon waveguides by selective epitaxial growth. Optical bandwidth of up to $120 \mathrm{GHz}$ can be achieved in practice in a $10 \mu \mathrm{m}$ long Ge photodetector. In addition, a responsivity of $0.8 \mathrm{~A} / \mathrm{W}$ at $1550 \mathrm{~nm}$ was measured [4,5]. In L. Vivien, et al. [4], pin germanium photodetectors selectively grown at the end of silicon waveguides are described.

\subsubsection{Optical modulators, based on p-n junctions.}

D.J. Thomson et al. [6] and G.T. Reed et al. [7] demonstrated modulators at $40 \mathrm{~Gb} / \mathrm{s}$ on silicon-on-insulator using the carrier depletion effect in a MZI configuration. A p-n junction is set up at the edge of the waveguide rib by doping with n-type and p-type on the opposite sides of the waveguide. During reverse bias, due to higher n-type doping the depletion region extends mainly into the waveguide rib. The highly doped regions in turn provide ohmic contacts to coplanar waveguide electrodes for driving the device. It was a part of HELIOS under FP7. In a recent demonstration, modulation at $50 \mathrm{~Gb} / \mathrm{s}$ has been achieved by D.J. Thomson et al. [8].

\subsubsection{Tuning elements, based on thermo-optic tuning.}

Thermal tuning of cavity resonances can be achieved by making contact pads of Ti/ TiN, Cu etc. as shown by W. Bogaerts, et al [9] and Dries Van Thourhout, et al. [10]. Heater technology allows demonstrating on-chip wavelength tunability of components.

\subsection{Standardization rules}

A level of process/device performance metrics will be agreed across foundries:

- Basic benchmarks will be set up for (standardized) passive and active devices. Examples are waveguide loss, detector sensitivity, modulator insertion loss, etc.

- The fabs will implement these metrics and data will be publicly available. This will allow customers to get a better view of process performance. The implementation of these metrics based on wafer test capabilities developed also in ePIXfab, will be included in the foundry price.

\section{PACKAGING}

In order to make silicon photonic IC technology useful for companies to evaluate, access to packaged devices and devices with a level of integration with electronic driver circuits is needed. ePIXfab will foremost setup access to low-cost package solutions for R\&D purposes. In addition, the ePIXfab partners have hybrid integration solutions in house that they offer complementary to the platform. 
In addition to low-cost photonic packaging solutions, there is an increasing demand for dense photonicselectronics integration. However, access to providers of dense integration of high-speed electronics and photonics is limited and prohibitively expensive. Rather, ePIXfab will offer a co-packaging or flip-chip solution which supports integration of electronic control circuitry, leading to integrated photonic sub-systems which can be more easily and comprehensively evaluated by the end-user.

\section{CONCLUSION}

Since 2006, ePIXfab has provided Multi Project Wafer access to silicon photonics technologies, setup training and design kits. ePIXfab was initially a collaboration between IMEC and CEA-LETI. The ESSenTIAL project expands the food chain around ePIXfab through partners - IHP GmbH (Germany), VTT (Finland), TNO (Netherlands), Tyndall Institute (Ireland) and CMC (Canada). In this manner, ePIXfab expands his service by (1) providing easy access to SMEs by performing evaluation studies, (2) offering a cost-sharing packaging for the easy characterization of the devices, (3) offering novel standardized building blocks such us optical modulators, thermal tuning elements and Ge photodiodes, and (4) offering hands-on training activities for the novel Silicon Photonics platform users.

\section{ACKNOWLEDGEMENTS}

The authors would like to kindly acknowledge the European Union for its support via the grant for the coordinated support action ESSenTIAL (FP7- 288702).

\section{REFERENCES}

[1] hittp://epixfab.eu/

[2] http://photonfab.eu/

[3] http://www.europractice.com/

[4] L. Vivien, A. Polzer, D. M.-Morini, J. Osmond, J.M. Hartmann, P. Crozat, E. Cassan, C. Kopp, H. Zimmermann, and J.M. Fédéli, "Zero-bias 40Gbit/s germanium waveguide photodetector on silicon," Opt. Express 20, pp. 1096-1101, 2012.

[5] L. Vivien, J. Osmond, J.-M. Fédéli, D. M.-Morini, P. Crozat, J.-F. Damlencourt, E. Cassan, Y. Lecunff, and S. Laval, "42 GHz p.i.n Germanium photodetector integrated in a silicon-on-insulator waveguide," Opt. Express 17, pp. 6252-6257, 2009

[6] D. J. Thomson, F. Y. Gardes, Y. Hu, G. Mashanovich, M. Fournier, P. Grosse, JM. Fedeli, and G. T. Reed, "High contrast $40 \mathrm{Gbit} / \mathrm{s}$ optical modulation in silicon," Opt. Express, vol. 19, pp. 11507-11516, 2011.

[7] G.T. Reed, D.J. Thomson, F.Y. Gardes, N.G. Emerson, J.-M. Fedeli, "40 Gb/s Silicon optical modulators," in Proc. Photonics Conference (PHO), 2011 IEEE, pp. 737-738, 2011.

[8] D. J. Thomson, F. Y. Gardes, J. M. Fedeli, S. Zlatanovic, Y. Hu, B.P. P. Kuo, E. Myslivets, N. Alic, S. Radic, G. Z. Mashanovich, and G.T. Reed, "50 Gbit/s silicon optical modulator," IEEE Photon. Technol Lett., vol. 24, no. 4, pp. 234-236, Feb. 2012.

[9] W. Bogaerts, P. De Heyn, T. Van Vaerenbergh, K. De Vos, S. Kumar Selvaraja, T. Claes, P. Dumon, P. Bienstman, D. Van Thourhout, R. Baets, "Silicon microring resonators", Laser Photonics Rev. 6, no. 1, pp. $47-73,2012$.

[10] D. Van Thourhout, T. Spuesens, S.K. Selvaraja, L. Liu, G. Roelkens, R. Kumar, G. Morthier, P. RojoRomeo, F. Mandorlo, P. Regreny, O. Raz, C. Kopp, and L. Grenouillet, "Nanophotonic devices for optical interconnect", IEEE J. Sel. Topics in Quantum Electron., vol. 16, no. 5, pp. 1363-1375, 2010. 